\title{
Feed in summer, rest in winter: microbial carbon utilization in forest topsoil
}

\author{
Lucia Žifčáková ${ }^{1,2^{*}}$ (D) Tomáš Větrovský1, Vincent Lombard ${ }^{3,4}$, Bernard Henrissat ${ }^{3,4,5}$, Adina Howe ${ }^{6}$ and Petr Baldrian ${ }^{1}$
}

\begin{abstract}
Background: Evergreen coniferous forests contain high stocks of organic matter. Significant carbon transformations occur in litter and soil of these ecosystems, making them important for the global carbon cycle. Due to seasonal allocation of photosynthates to roots, carbon availability changes seasonally in the topsoil. The aim of this paper was to describe the seasonal differences in $C$ source utilization and the involvement of various members of soil microbiome in this process.

Results: Here, we show that microorganisms in topsoil encode a diverse set of carbohydrate-active enzymes, including glycoside hydrolases and auxiliary enzymes. While the transcription of genes encoding enzymes degrading reserve compounds, such as starch or trehalose, was high in soil in winter, summer was characterized by high transcription of ligninolytic and cellulolytic enzymes produced mainly by fungi. Fungi strongly dominated the transcription in litter and an equal contribution of bacteria and fungi was found in soil. The turnover of fungal biomass appeared to be faster in summer than in winter, due to high activity of enzymes targeting its degradation, indicating fast growth in both litter and soil. In each enzyme family, hundreds to thousands of genes were typically transcribed simultaneously.

Conclusions: Seasonal differences in the transcription of glycoside hydrolases and auxiliary enzyme genes are more pronounced in soil than in litter. Our results suggest that mainly fungi are involved in decomposition of recalcitrant biopolymers in summer, while bacteria replace them in this role in winter. Transcripts of genes encoding enzymes targeting plant biomass biopolymers, reserve compounds and fungal cell walls were especially abundant in the coniferous forest topsoil.
\end{abstract}

Keywords: Auxiliary activity enzymes, Bacteria, Carbon cycle, Carbohydrate-active enzymes, Coniferous forests, Decomposition, Fungi, Glycoside hydrolases, Lignocellulose-degradation, Seasonality, Transcriptomics

\section{Background}

Coniferous forests in the boreal and temperate zones of the Northern Hemisphere represent significant global carbon pools and sinks [1]. Consequently, understanding the processes of the carbon $(\mathrm{C})$ cycle and its changes during the year is essential for modeling potential impacts of global climate change on these ecosystems. Forest ecosystems are influenced by trees that mediate the influx of $\mathrm{C}$ into the ecosystem pool and contribute to soil respiration and carbon deposition, which are important microbial-mediated processes [2-4], although the relative share of fungi and

\footnotetext{
* Correspondence: zifcakoval@gmail.com

'Institute of Microbiology of the CAS, Vídeňská 1083, 14220 Praha 4, Czech Republic

${ }^{2}$ Faculty of Science, Charles University, Albertov 6, 12843 Praha 2, Czech

Republic

Full list of author information is available at the end of the article
}

bacteria and effect of the seasonality on these processes, remains largely undiscovered.

In the coniferous forest floor, litter and soil represent largely different compartments when considering $\mathrm{C}$ cycling processes $[5,6]$. The litter is derived from recalcitrant plant biopolymers (cellulose, hemicelluloses, and lignin). In contrast, soil is a mixture of highly recalcitrant materials, such as polyphenols-products of lignin degradation, and has a low abundance of plant biopolymers. The tree roots exude photosynthesis-derived labile $\mathrm{C}$ compounds that enter soil both directly and through root-associated ectomycorrhizal fungi (ECM) $[3,5]$. Another important $C$ pool is found in living biomass of microbiota (chitin and peptidoglycan) or in storage compounds (starch, glycogen, and trehalose) [7-9].

The difference in the content of $\mathrm{C}$ matter between horizons of forest floor leads to the microbial community stratification $[5,7,10]$. Litter is rich in saprotrophic taxa, 
while ECM fungi, mostly represented by Basidiomycota in our ecosystem [5], tend to dominate the soil [11]. The relative abundance of bacteria increases with depth, and the composition of their communities differs in litter and soil as well [5].

The turnover of $\mathrm{C}$ compounds can be tracked by the analysis of enzymes that mediate them-the carbohydrate-active enzymes (CAZymes). Specifically, glycoside hydrolases (GH) and selected auxiliary activity enzymes (AA) are associated with the decomposition of polysaccharides and lignin, respectively [12]. The classification of GH and AA proteins or genes into families that contain structurally similar proteins makes it possible to assign catalytic functions to sequences using CAZy pipeline [12].

CAZymes have previously been studied in forest soil transcriptomes, though only by approaches targeting individual genes by PCR $[5,13]$ or exclusively eukaryotic transcripts at low throughput exploiting Sanger sequencing [14]. While previous studies of litter proteomes have indicated the dominance of fungal decomposition enzymes over bacterial ones [15], the results of stable isotope probing experiments indicate that fungi and bacteria are both involved significantly in cellulose and hemicellulose utilization in forest soils [16-19]. On the other hand, bacteria dominated in the utilization of dead fungal biomass, which is an important pool of $C$ in forest topsoil [20]. The results of aforementioned studies indicate that fungi and bacteria are involved in decomposition of different substrates, but the share of fungi and bacteria in degradation of these substrates is still unknown.

Seasonality in temperate forest soils is composed of individual and well documented factors controlling soil microbial communities [21-27], such as a change in soil moisture, soil temperature, and plant activity that strongly affects $\mathrm{C}$ cycling in forest ecosystems [28]. One of the approaches to study the effect of seasonality on $\mathrm{C}$ cycling is to measure activities of microbial CAZymes in the studied environment. It was found that activities of CAZymes depend on temperature as the main driving factor of seasonal differences in enzymatic activities in the tundra [29]. Temperature may cause decline of CAZymes activities in the cold season compared to the activities in the warm season in both boreal coniferous forest [30] and in temperate spruce forest [31], and thus also negatively affect $C$ cycling. Changes in the $C$ cycling by microbial community and in the composition of microbial community were observed between summer and winter in mixed temperate forest [32] as well as in an arctic system [33]. Dominance of saprotrophic fungi, which are largely responsible for degradation of lignocellulose [34], in spring and ECM fungi, which are involved in plant derived C storage in soil [3], in late summer was shown for the temperate and boreal forests [35-39]. In case of ECM fungi, it is thought to be supported by maximal growth of spruce fine roots in the summer, with which they are symbiotic [40]. Bacterial community composition also responded to the seasonal changes in temperate forest $[10,41]$ and alpine soils $[28,42]$, and it was interpreted as a reaction to $\mathrm{C}$ fluctuations in plant roots exudates during the year as well as with variation in moisture and temperature of soil.

The photosynthetic activity of trees during the summer period is high (with favorable temperature and light conditions), while it is minimal in winter, when it is reduced by light limitations and temperatures below the freezing point. Consequently, carbon allocation belowground varies dramatically and directly impacts soil biota [4, 43]. In our previous study, we have demonstrated that the presence of microbial communities in the coniferous Picea abies forest topsoil is similar among seasons, but their activities differ dramatically [44]. The pool of transcripts differs among seasons, especially in the soil, where fungal transcripts were observed to significantly decrease (by $50 \%$ ) in winter, with ECM-associated activity being particularly reduced [44].

The consequences of seasonality on the $\mathrm{C}$ cycle in soil are not well known, but it can be hypothesized that the reduced input of photosynthates in the form of root exudates in winter, and continuous demand of microorganisms for $\mathrm{C}$ sources would be seen as an increase in the transcription of genes encoding CAZymes for the utilization of recalcitrant plant $C$ compounds, such as cellulose and hemicellulose by saprotrophic bacteria and fungi. To survive the winter season, we expect ECM fungi to subsist on plants storage compounds, such as starch, or on their own storage compounds, such as glycogen and trehalose, and to transcribe the genes for relevant CAZymes, such as amylases and trehalases, respectively.

In this study, for the first time, we describe the contribution of fungi and bacteria to CAZyme pool in two different seasons, summer and winter, leveraging the power of metagenomics and metatranscriptomics with sufficient reliability and resolution. We use metagenomics to characterize functional potential of individual taxa for CAZyme production, and metatranscriptomics to describe the contribution of microorganisms to CAZyme share between seasons and so mediated effect on C-cycling.

\section{Methods}

\section{Sampling area and sample collection}

The study sites were located in the highest altitudes of the Bohemian Forest National Park, Czech Republic $\left(49^{\circ} 2^{\prime}\right.$ $\left.38^{\prime \prime} \mathrm{N}, 13^{\circ} 37^{\prime} 2^{\prime \prime} \mathrm{E}\right)$, covered by an unmanaged Norway spruce (P. abies) forest. The mean annual temperature was $5{ }^{\circ} \mathrm{C}$, and the mean annual precipitation was $1000 \mathrm{~mm}$. The soil temperatures at the days of sampling were recorded and can be find in the study of [44], but the soil moisture was not recorded. When the understory was present, it was 
composed of grasses (Avenella, Calamagrostis), bilberries (Vaccinium), mosses, and ferns. This study used the samples of DNA and RNA collected in July 2012 and March 2013 previously described in the study of [44]. Briefly, six samples were taken from the litter layer $(\mathrm{L})$ and the organic horizon of soil (S). After removal of roots, L material was cut into $0.5 \mathrm{~cm}$ pieces and was mixed, while $\mathrm{S}$ material was passed through a $5-\mathrm{mm}$ sterile mesh and was mixed. A total of 24 samples were collected (six sites $\times$ two seasons $\times$ two horizons). Samples were immediately frozen in liquid nitrogen and stored at $-80{ }^{\circ} \mathrm{C}$ until analysis.

\section{Extraction and analysis of environmental RNA and DNA}

For all 24 samples, RNA and DNA extraction, the metatranscriptome sequencing and assembly were described previously by [44]. Briefly, RNA was extracted using the RNA PowerSoil Total RNA Isolation Kit (MoBio Laboratories) combined with the OneStep PCR Inhibitor Removal Kit (ZymoResearch) from three 1-g aliquots per sample, pooled, and RNA-purified using the RNA Clean \& Concentrator kit (ZymoResearch) on a column treated with DNase I (Fermentas). Approximately $1 \mu \mathrm{g}$ of RNA was treated with an equimolar mixture of RiboZero rRNA Removal Kits Human-Mouse-Rat and Bacteria (Epicenter) and a total of 50 ng of treated RNA served as the input for the ScriptSeq v2 RNA-Seq Library Preparation Kit (Epicenter) that was used for library construction. Total DNA was extracted in triplicate from all samples as showed in [44]. DNA samples were fragmented to reach the mean fragment lengths around $400 \mathrm{bp}$ and libraries were prepared using TruSeq PCR Free Kit (Illumina). Metatranscriptome and metagenome libraries were sequenced on an Illumina HiSeq2000 to generate 150-base paired-end reads.

Metagenome reads were processed in the same way as originally described for the metatranscriptome [44]. The reads were quality trimmed by removing adapters with Trimmomatic (v 0.27) using Illumina TruSeq2-PE adapters with a seed mismatch threshold, palindrome clip threshold, and simple clip threshold set at 2,30 , and 10 , respectively [45]. Furthermore, sequencing reads were filtered by base call quality using the FASTX-Toolkit (http://hannonlab.cshl.edu/ fastx_toolkit/index.html), specifically fastq_quality_filter, with the following parameters: -Q33 -q 30 -p 50. Resulting sequences were normalized using methods previously described in [46, 47] and Khmer ( $\mathrm{v}$ 0.7.1) and command normalize-by-median.py with the following parameters: $-\mathrm{k}$ 20 -C 20 -N 4 - x 50e9. Next, errors were trimmed by removing low abundance fragments of high coverage reads with Khmer and command filter-abund.py -V. The paired-end assembly of the remaining reads was performed with the Velvet assembler ( $\mathrm{v}$ 1.2.10, -exp_cov auto -cov_cutoff auto -scaffolding on [48]) using odd k-mer lengths ranging from 33 to 63 . Resulting assembled contigs were merged using CD-HIT v4.6 [49, 50] and minimus2 Amos v3.1.0 [51].
Assembly of metagenomic reads was performed in the same way as described for the metatranscriptome and sequence data of all contig sequences have been deposited in the MG RAST public database [52] under the dataset number 4627252.3; metatranscriptome contigs are available as 4544233.3. Metagenome sequencing yielded $567 \times 10^{6}$ reads $\left(24 \times 10^{6} \pm 2 \times 10^{6}\right.$ reads per sample) that were assembled into 9,380,309 contigs over 200 bases, including 1,882,204 contigs over 500 bases, 569,720 over 1000 bases and 6665 over 10,000 bases (mean length was 454 bases). The longest contig had a length of 179,090 bases. Protein prediction in MG-RAST yielded a total of 9,178,489 predicted coding regions, of which 4,355,554 (47.5\%) have been assigned an annotation by MG RAST.

\section{Annotation of the metagenome and metatranscriptome}

Contig annotation was first performed in MG RAST with an $\mathrm{E}$ value threshold of $10^{-5}$ while also considering the representative hit option (i.e., single best annotation for each feature) and taxonomic information was retrieved for each identified contig. Because MG RAST is not suitable for annotation of fungal proteins, predicted proteins were subsequently annotated by finding the best protein match in an in-house database containing protein predictions from all publicly available fungal genomes available at the time of analysis (155 genomes). For all hits that received closer hit in terms of $\mathrm{E}$ value to the fungal-predicted protein database (FPPD) then using MG RAST, taxonomic information was retrieved from the FPPD.

Glycoside hydrolases (GH) and auxiliary enzymes (AA) were identified among the metagenome and metatranscriptome contigs using the CAZy pipeline [12], which combines Blast and HMM tools with the manual curation of CAZy database (http://www.CAZy.org). Protein models are compared with the sequence and profile libraries created from catalytic and non-catalytic modules of the CAZy database. GH and AA families were grouped based on which substrate they act upon, with the guidance of Dr. Bernard Henrissat, the founder of CAZy database (Table 1). We considered AA families to be involved in degradation of lignin because lignin is always found in union with polysaccharides in the plant cell wall and thus AA fill a variety of enzyme mechanisms to act on substrates related to lignocellulose conversion [53].

To assess the abundance in the metagenome and the relative rate of transcription in the metatranscriptome, individual sequence reads from each sample were mapped onto contigs identified as GH or AA using bowtie 2.2.1 [54] with the default settings of end to end alignment-sensitive. To calculate gene or transcript abundance, data were expressed as: per base coverage $=$ read count $\times$ read length/contig length. Abundances were always reported as normalized values, i.e., shares of all transcripts in given sample, or, 
Table 1 Functional classification of glycosyl hydrolases and auxilliary used in this paper based on their characterized catalytic activities according to CAZy (http://www.CAZy.org)

\begin{tabular}{|c|c|c|}
\hline Group & Target & GH families \\
\hline Cellobiose & Cellooligosaccharides & $\begin{array}{l}\text { GH1 ( } \beta \text {-glucosidase/ } \beta \text {-xylosidase), GH3 ( } \beta \text {-glucosidase/ } \beta \text {-xylosidase/endoxylanase), GH1 } 16 \\
\text { ( } \beta \text {-glucosidase/ } \beta \text {-xylosidase) }\end{array}$ \\
\hline Cellulose & Plant cell wall & $\begin{array}{l}\text { GH5_1, GH5_2, GH5_4, GH5_5, GH5_25, GH5_26, GH5_38, GH5_39, GH5_46 (endocellulase), } \\
\text { GH6 (exocellulase/endocellulase), GH7 (exocellulase/endocellulase), GH8 } \\
\text { (endocellulase/endoxylanase), GH9 (exocellulase/endocellulase/endoxylanase/ } \\
\text { ß-glucosidase), GH12 (endocellulase/endoxylanase), GH44 (endocellulase/endoxylanase), } \\
\text { GH45 (endocellulase), GH48 (exocellulase/endocellulase/chitinase), GH74 (endocellulase), } \\
\text { AA9 (lytic polysaccharide monooxygenase) }\end{array}$ \\
\hline Chitin & Glucans fungal cell wall & $\begin{array}{l}\text { GH5_9, GH5_14, GH5_15 ( } \beta \text {-1,3-glucanase/ } \beta \text {-1,6-glucanase), GH16 (endo-1,3- } \beta \text {-glucanase/ } \\
\text { endo-1,3- } \beta \text {-galactanase), GH17 (endo-1,3- } \beta \text {-glucosidase/ } \beta-1,3-\beta \text {-glucosidase), GH18 } \\
\text { (chitinase), GH19 (chitinase), GH20 ( } \beta \text {-hexosaminidase), GH72 ( } \beta-1,3-\text {-glucanosyltransglycosylase) }\end{array}$ \\
\hline Lignin & Plant cell wall & $\begin{array}{l}\text { AA1 (laccase), AA2 (peroxidase), AA3 (oxidase), AA4 (oxidase), AA5 (oxidase), AA6 (oxidase), } \\
\text { AA12 (oxidase) }\end{array}$ \\
\hline Pectin & Plant cell wall & $\begin{array}{l}\text { GH5_7, GH5_8, GH5_10, GH5_17, GH5_19, GH5_36 ( } \beta \text {-mannanase/endo- } \beta \text {-1,4-mannanase), } \\
\text { GH28 (polygalacturonase/rhamnogalacturonase), GH62 (a-L-arabinofuranosidase), GH78 } \\
\text { (a-Lrhamnosidase), GH88 ( } \beta \text {-glucuronyl hydrolase), GH105 (glucuronyl hydrolase/galacturonyl } \\
\text { hydrolase), GH106 (a-L-rhamnosidase) }\end{array}$ \\
\hline Peptidoglycan & Bacterial cell wall & GH22 (lysozyme), GH23 (lysozyme), GH24 (lysozyme), GH25 (lysozyme), GH108 (lysozyme) \\
\hline Starch/glycogen & Storage compounds & $\begin{array}{l}\text { GH13 (amylase/a-glucosidase/trehalase), GH14 (amylase), GH15 (glucoamylase/glucodextranase) } \\
\text { GH31 (a-glucosidase), GH57 (amylase), GH77 (amylomaltase), GH119 (amylase) }\end{array}$ \\
\hline Trehalose & Storage compounds & GH37 (trehalase), GH65 (trehalase) \\
\hline Xylan & Plant cell wall & $\begin{array}{l}\text { GH5_22 ( } \beta \text {-xylosidase), GH10 (endo-1,4- } \beta \text {-xylanase/endo-1,3- } \beta \text {-xylanase), GH11 (endoxylanase), } \\
\text { GH30 (endoxylanase/ } \beta \text {-xylosidase/ } \beta \text {-glucosidase), GH67 (xylan a-1,2-glucuronidase), GH115 } \\
\text { (xylan a-1,2-glucuronidase), GH120 ( } \beta \text {-xylosidase) }\end{array}$ \\
\hline
\end{tabular}

where indicated, shares of all transcripts of a selected microbial taxon.

\section{Statistical analysis}

R [55] and PAST 3.03 (http://folk.uio.no/ohammer/past/) were used for statistical analysis. Differences in relative abundances of gene or transcript abundances were tested using the Mann-Whitney $U$ test with the Bonferroni correction for multiple comparisons. The Mann-Whitney $U$ assumes the measurements on a rank-order scale but does not assume normality of data. One-way or two-way PERMANOVA on Bray-Curtis distances with 99,999 permutations was used to analyze differences among communities or transcript pools. Two-dimensional non-metric multidimensional scaling (NMDS) ordination analysis on Bray-Curtis distances was performed in $\mathrm{R}$ with package vegan $[55,56]$. In all cases, differences at $P<0.05$ were considered to be statistically significant.

\section{Results}

\section{Transcription of genes encoding auxiliary enzymes and glycoside hydrolases}

Thirteen percent of 4.5 million of all contigs from $P$. abies topsoil metatranscriptome were assigned to carbohydrate metabolism [44], while the rest of transcripts belonged mainly to housekeeping genes and other metabolic pathways [44]. 42,872 (0.83\%) transcripts were identified as $\mathrm{GH}$ belonging to 105 families and 5111
$(0.11 \%)$ as AA belonging to 12 families. The transcription of $\mathrm{GH}$ represented between 0.26 and $0.34 \%$ of the total transcription in both litter and soil. AA were more transcribed in litter $(0.07-0.08 \%$ of total transcription) than in soil (0.03-0.04\%; Fig. 1a). GH13 (amylase) was the most diverse family with 4574 contigs followed by GH5 (mixed activities on cellulose, hemicellulose and pectin) (2011 contigs), GH3 ( $\beta$-glucosidase) (1707 contigs). High diversity of transcription was found in families AA3 (mixed activities on lignocellulose) (1683 contigs) and AA1 (laccase) that had more than 1000 contigs (Additional file 1: Table S1).

$\mathrm{GH}$ and AA transcripts were more frequently of fungal origin (43\% GH and $71 \% \mathrm{AA}$ ) then of bacterial origin (42 and $22 \%$ ). Most $\mathrm{GH}$ and AA transcripts were transcribed by fungi that accounted for $51.6 \%$ of GH reads $(27.6 \%$ Basidiomycota, $19.3 \%$ Ascomycota) and as much as $81.5 \%$ of AA reads (44.7\% Ascomycota, 35.1\% Basidiomycota). Bacteria were responsible for $34.7 \%$ of $\mathrm{GH}$ transcription (Acidobacteria 13.7\%, Proteobacteria 7.6\%), and $13.1 \%$ of AA transcription. $\mathrm{GH}$ were also frequently transcribed by animals $(3.7 \%)$ and plants $(2.6 \%)$ and AA by plants $(3.3 \%$; Fig. 1b, c). It was apparent that groups of organisms are significantly different in enzyme sets they produce (Fig. 2b). All taxa transcribe $\alpha$-glucosidases and cellulases, however, fungi had the highest share on transcription of cellulases and ligninolytic enzymes. All species also transcribed $\beta$-glucosidases and chitinases, while archaea did 


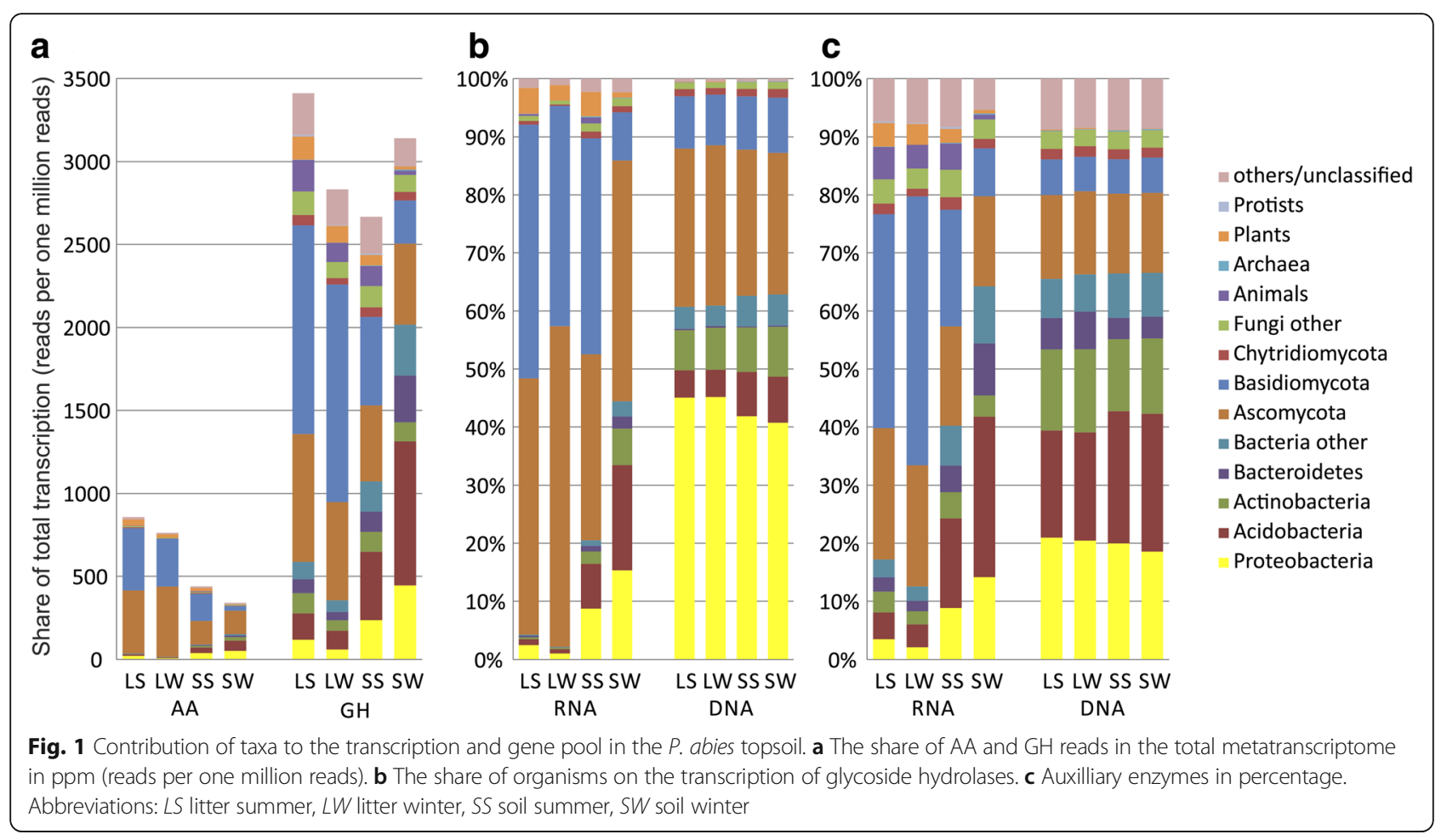

not transcribe xylanases and only some Proteobacteria transcribe xylanases (Additional file 1: Table S2). In plants, the most transcribed genes belonged to AA2 (class II peroxidase), AA1 (laccase), GH27 ( $\alpha$-galactosidase), and GH38 (mannosidase). The contribution of individual groups to the production of CAZymes was highly variable with a high contribution of fungi to the production of the dominant plant cell wall-degrading enzymes-cellulases, ligninases (up to $90 \%$ of fungal transcripts in both groups), and xylanases (up to 70\%); all other enzyme groups were produced by a wide range of taxa (Figs. 3 and 4).
Among the functional groups of CAZymes as defined in Table 1, the ones targeting cellulose were most transcribed followed by those acting on lignin, fungal cell wall, and starch and glycogen. Most metatranscriptome reads were associated with the $\alpha$-glucosidases of the GH13 family, with the cellulolytic enzymes in families GH5 (subfamilies 1, 2, 4, 5, 25, 26, 38, 39, 46), GH7 and AA9, ligninolytic oxidases AA3, endoglucanase/endogalactanase GH16, and with the chitinase GH18 (Fig. 4). Among cellulolytic genes, transcripts from AA9 family were very abundant in litter (27\% in summer and $40 \%$ in

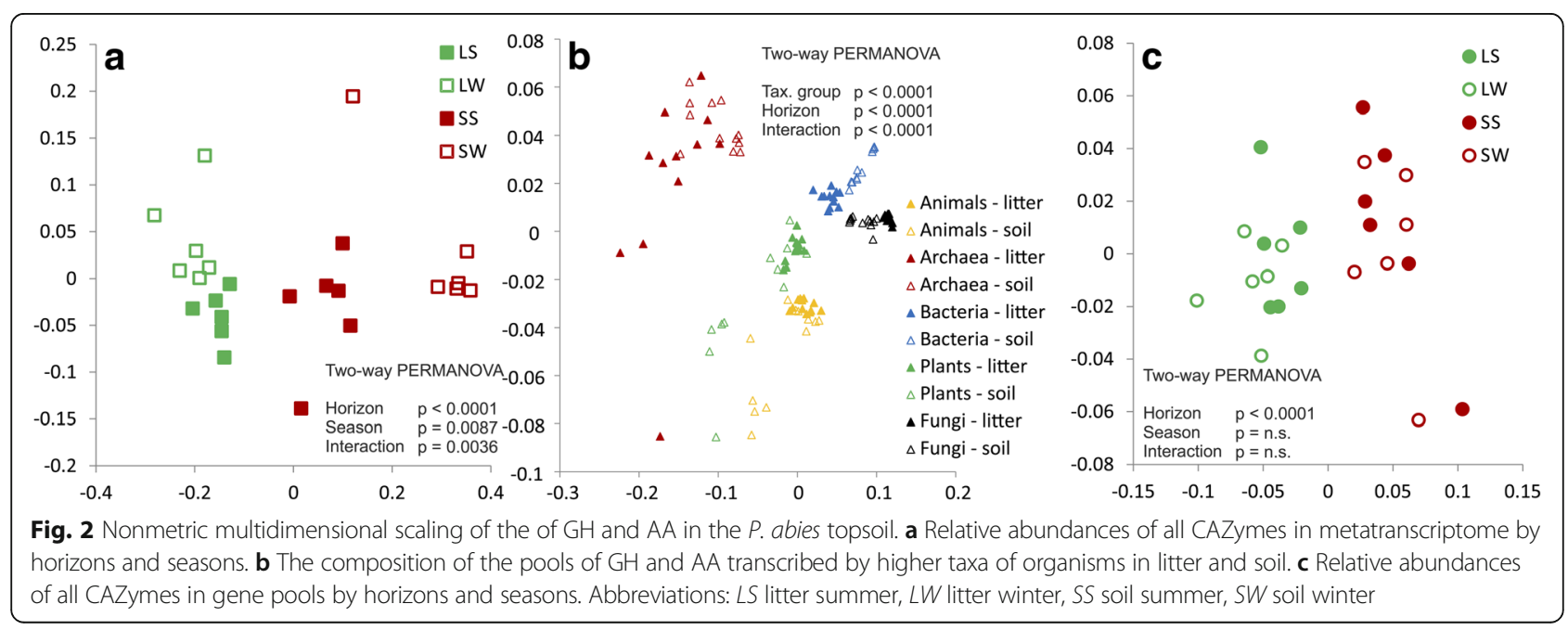




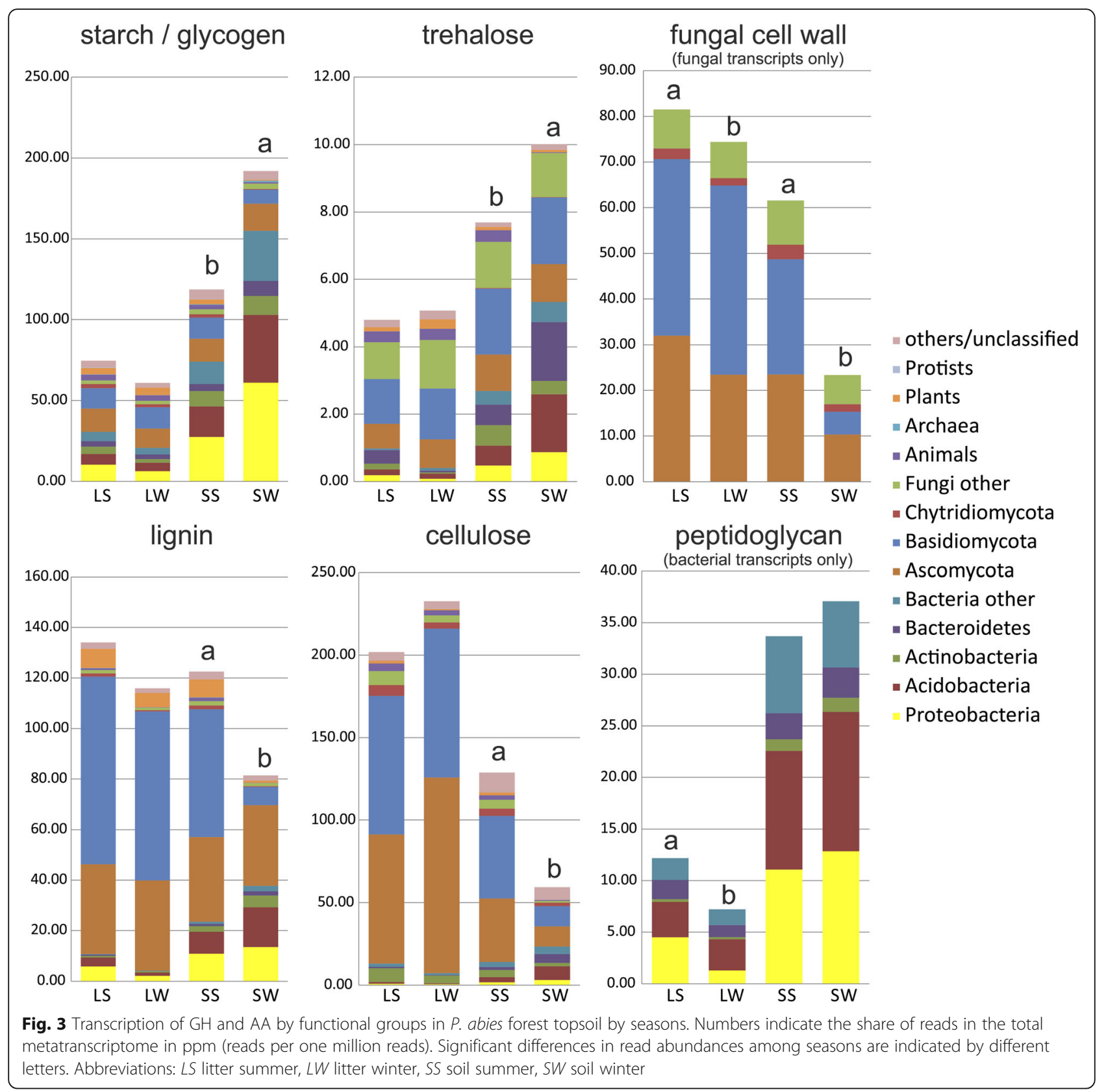

winter), while transcripts of GH7 family were mostly produced in summer in both horizons (36\%).

The transcript pool differed significantly between litter and soil: 86 gene families showed significantly different transcription rate between horizons (Additional file 1: Table S1), which probably reflects differences in microbial community composition $[5,44]$ as well as differences of $C$ sources between horizons [6]. Soil samples showed higher transcription of CAZymes targeting reserve compounds (starch/glycogen and trehalose) and peptidoglycan, while the genes encoding enzymes degrading cellulose and lignin and pectin were more transcribed in litter (Fig. 3), which suggests different source utilization between horizons, with plant-derived polymers to be more important $\mathrm{C}$ source in litter, while dead biomass of bacteria and root exudates in soil.

\section{Seasonality of transcription}

The transcript pools differed significantly between summer and winter in both horizons but seasonality was more pronounced in soil, where it affected $60 \mathrm{CAZy}$ gene families compared to 18 families in litter (Fig. 2a, Additional file 1: Table S1). At the level of functional groups of CAZymes, differences in their metagenome content among seasons was negligible as well as the variation in the taxonomic groups that produced them 


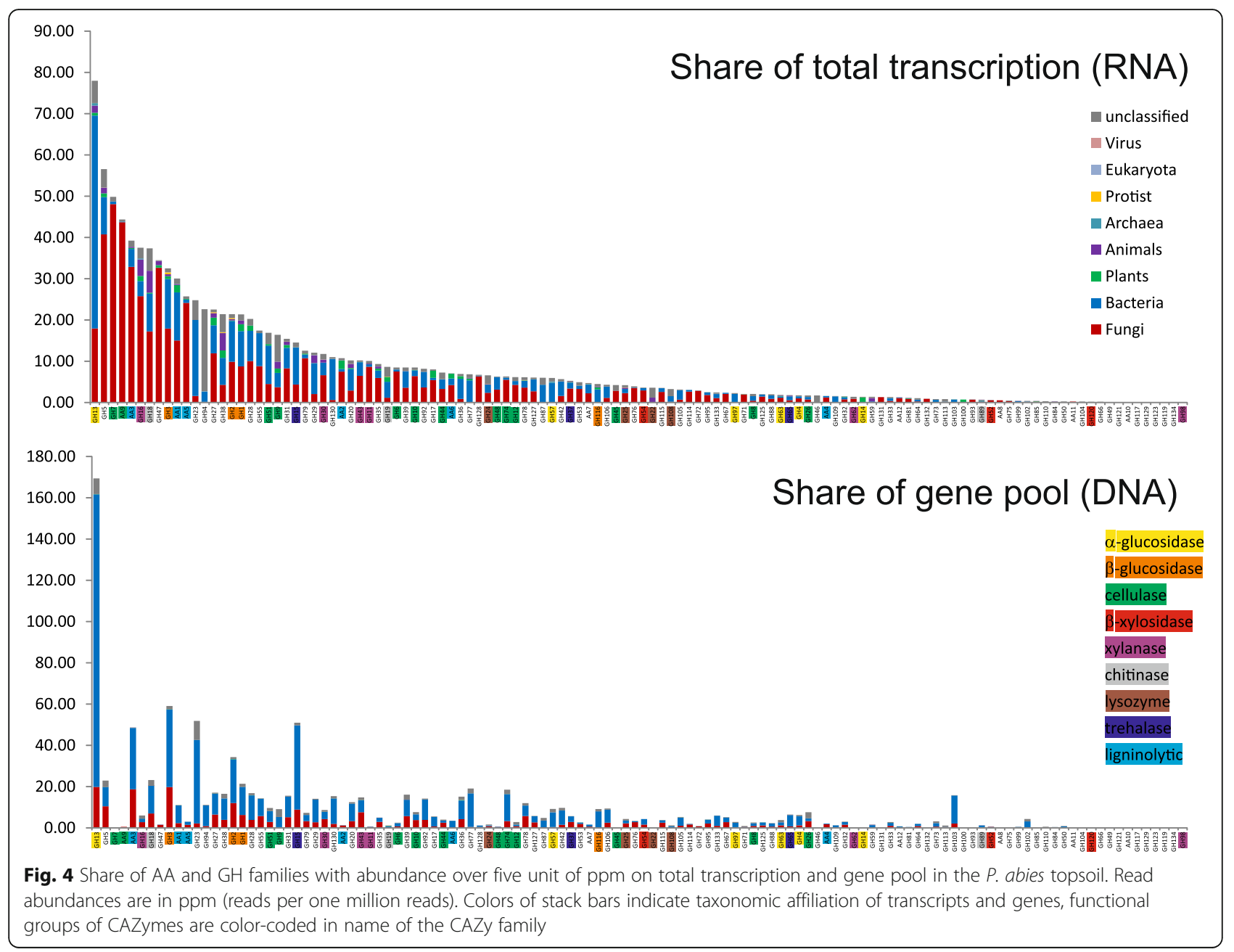

(Additional file 2: Figure S1). Most of seasonal differences in transcription among the functional groups of CAZymes as classified in Table 1 and the shift in the contribution of taxa to their production (Fig. 3) was found especially in soil.

Winter samples were marked by an increase in the use of reserve compounds (glycogen/starch and trehalose) while the share of CAZymes targeting recalcitrant plant biomass (cellulose and lignin) decreased. Significantly higher transcription of CAZymes targeting fungal cell wall components, such as chitin, and selected glucans was observed in summer compared to winter (Fig. 3), indicating higher turnover and growth rates in the warm season. Transcription of CAZymes involved in bacterial peptidoglycan degradation in litter was also higher in summer than in winter. For all enzyme groups, the share of CAZymes transcribed by fungi in soil decreased in winter while the contribution of bacteria increased (Fig. 3). For example, fungi transcribe $62 \%$ of cellulases in soil in summer but only $29 \%$ in winter.
Of 2836 CAZyme-associated transcripts that appeared in at least five litter samples, 219 (7.7\%) were significantly increased in summer and 103 (3.6\%) in winter. In soil, of 2119 transcripts, 287 (13.5\%) were increased in summer and 215 (10.1\%) in winter confirming more dramatic change in distribution of transcripts in soil than in litter. In soil, CAZymes significantly more transcribed in summer were those targeting cellulose, lignin and microbial cell walls, while CAZymes targeting starch, glycogen, and trehalose were more frequently transcribed in winter (Fig. 3, Additional file 3: Figure S2).

Gene pool of auxiliary enzymes and glycoside hydrolases Among genes predicted in soil metagenomes, $5.5 \%$ of genes were annotated as CAZymes and the annotations for the rest of gene families can be found in study of [44]. In total, 91,195 GH from 108 families and 7709 AA from 11 families were identified among the protein predictions of the $P$. abies topsoil metagenome. GH13 was the most diverse family with 16,412 contigs followed by 
GH3 and GH15 (trehalase) and another 29 GH families and the family AA3 were identified in $>1000$ contigs (Fig. 4, Additional file 1: Table S1). Most abundant families in metagenome were GH13, GH3, GH23 (chitinase), GH15, AA3, GH2 ( $\beta$-glucosidase), GH18 (chitinase), GH5 (cellulolytic subfamilies 1, 2, 4, 5, 25, 26, 38, 39, 46), and GH1 ( $\beta$-glucosidase) (Fig. 4) in total representing approximately one half of all reads.

Among contigs identified as $\mathrm{GH}, 67 \%$ were of assigned to bacteria and $27 \%$ to fungi and of AA $46 \%$ were of bacterial and $24 \%$ of fungal origin. Considering the frequency of occurrence, $66.2 \%$ of glycoside hydrolase reads were assigned to bacteria (Proteobacteria 20.0\%, Acidobacteria 20.9\%, Actinobacteria 13.4\%, Bacteroidetes $4.9 \%$ ) and $24.9 \%$ to fungi (Ascomycota 14.1\%, Basidiomycota $6.1 \%$ ) (Fig. 1 b). Of auxiliary enzyme reads, $61.8 \%$ were assigned to bacteria (Proteobacteria 43.2\%, Acidobacteria $6.3 \%$, Actinobacteria $7.6 \%$ ) and $37.5 \%$ to fungi (Ascomycota 26.1\%, Basidiomycota 9.1\%). Reads assigned to other organisms were rare (Fig. 1c).

The gene pool differed significantly between litter and soil, but not between seasons (Fig. 2c). Relative abundance of 120 individual gene families was significantly different among horizons for 72 gene families but among season only for 9 gene families in litter and 2 gene families in soils, indicating that the community composition is horizon-specific but similar in both seasons (Additional file 1: Table S1).

\section{Discussion}

\section{Gene pool of CAZymes and its transcriptions}

Our results confirmed that all CAZy families were transcribed by many taxa at the same time and more isoforms of CAZymes were found in the genomes of the most abundant species of bacteria binned from metagenome (data not shown), which suggest high functional redundancy in soil environment, confirming the observations previously made for another functional gene cellobiohydrolase (cbhI), which was also produced simultaneously by hundreds of taxa [5].

The share of fungi in our metatranscriptome is two times higher than bacteria, while in the metatranscriptomic studies from a maple forest or in peatlands, bacterial CAZy transcripts were 2.6 to 5-fold more abundant then eukaryotic ones $[57,58]$. This may indicate high importance of fungi in coniferous forests, although the comparison may be biased by the fact that previous studies annotated short reads and used a limited reference database for fungi, so that relevant transcripts might have been overlooked. The observed dominance of fungal-associated CAZymes is consistent with previous results obtained by proteomic analysis of decomposing beech litter, where fungal transcripts also dominated the enzyme pool [15]. Compared to that study, we have observed a much higher share of transcripts from Basidiomycota, which is in agreement with their high abundance in the studied ecosystem [44].

Our data confirm that the share of bacterial reads in the metagenome is higher than in the metatranscriptome, while the opposite is true for fungal genes and transcripts. The low representation of eukaryotic genes that is generally reported from microbial metagenomic studies [59, 60] may be caused by the high abundance of non-coding DNA in eukaryotic sequences, which may be overcome by using eukaryotic metatranscriptomes that contain mostly coding sequences. Also, eukaryotic transcription is unrelated to the amount of gene copies in genomes because of its complex regulation [61]. Another cause of low eukaryotic abundance in metagenomes can be the underrepresentation of fungal and other eukaryotic genomes in genomic databases [62] and thus the inability to properly identify genes of these organisms.

CAZymes in both the metagenome and metatranscriptome, differed significantly in their composition between litter and soil. This is consistent with the fact that the composition of bacterial and fungal communities differs among horizons in the studied ecosystem [5] as well as elsewhere [10,63], reflecting the properties of these habitats, such as the availability of $C$ sources [64]. Litter was enriched in transcripts associated with cellulases and lignin-targeting enzymes, indicating the importance of decomposition of recalcitrant plant biopolymers. Soil showed an increased share of enzymes acting on glycogen and especially trehalose, which both are known reserve compounds of fungi, including ECM fungi [65].

\section{Involvement of soil organisms in C transformation}

The vast majority of GH and AA (83-92\% and $93-95 \%$, respectively) were encoded and transcribed by microorganisms, i.e. fungi, bacteria but the share of archaeal reads in metatranscriptome and metagenome was negligible. Fungi accounted for the higher share of AA transcription then bacteria, and this was also the case of $\mathrm{GH}$ transcription in litter; in soil, GH were produced equally by fungi and bacteria in summer, but bacteria largely dominated GH transcription in soil in winter.

The share of bacterial transcription of $\mathrm{GH}$ and $\mathrm{AA}$ was substantial in soil, and bacterial transcripts were associated with the majority of all CAZymes, the most abundant bacterial CAZymes were the ones involved in degradation of labile substrates, such as starch, cellobiose or other oligosaccharides. Concretely, bacterial GH13 genes, which are putative $\alpha$-glucosidases/ $\alpha$-amylases, were the most abundant in metagenomes and in metatranscriptomes as well. GH13 genes, were among the most abundant CAZymes genes present in bacterial genomes [66] and were also found to be abundant in another forest soil [59] and highly transcribed in peatlands 
[58]. Bacterial transcripts of CAZymes with chitinolytic activity confirmed important role of bacteria in the turnover of dead fungal mycelia [20].

Acidobacteria, Proteobacteria, Bacteroidetes, and Actinobacteria were the most abundant bacterial producers of CAZymes. These groups are known to be abundant in acidic forest topsoil [44] and have also been found to be dominant in CAZy production in another acidic environment-the boreal peatland [58]. The culturing and analysis of Acidobacteria, Proteobacteria, and Bacteroidetes from coniferous forests has confirmed the production of a wide range of extracellular enzymes by the individual members of these phyla, especially by the Acidobacteria and Bacteroidetes [67]. On the one hand, it was also showed that bacteria are able to produce a CAZymes that allow them to access $C$ in cellulose or hemicelluloses $[16,19,68]$. On the other hand, the decomposition of lignin, cellulose was dominated by fungi that appear to be better adapted to decompose recalcitrant plant-derived biomass components [69]. Fungal CAZymes that were associated with plant biomass decomposition were identified in dominant transcripts of both Ascomycota and Basidiomycota and were related to cellulolytic enzymes, namely, the GH7 cellulases and the AA9 lytic polysaccharide monooxygenases. Overall, the fungi are the major producers of CAZymes involved in lignocellulose degradation, while bacteria highly transcribed CAZymes involved in the degradation of storage compounds and bacterial and fungal cell walls. In other groups of organisms, for example plants, mannosidases of family GH38 and laccases of AA1 belonged to the most transcribed CAZymes. GH38 are necessary for the correct root development [70] and laccases perform many roles, such as lignin polymerization [71] and tissue repair [72].

\section{Seasonality of $\mathrm{C}$ utilization}

Here, we confirm the previous observation that composition of microbial communities in litter and soil in both seasons remains stable as observed elsewhere [73-75], but our results from the same ecosystem indicate that the ratio of fungi to bacteria and fungal biomass are significantly higher in summer than in winter [44]. We also show that transcripts of genes encoding enzymes for fungal and bacterial cell wall degradation are higher in summer than in winter, which may indicate higher growth rates in summer for fungi and bacteria, respectively. The seasonality of transcription of $\mathrm{GH}$ and $\mathrm{AA}$ was substantially higher in soil as it was also the case for total transcription in the studied ecosystem [44] and likely reflects the differences in seasonal fluctuations of C sources, of which tree photosynthates are highly important, being responsible for $30 \%$ of soil microbial respiration in coniferous forest soils [4].

The relative contribution to CAZyme transcription increased in soil in winter for presumed saprotrophs such as the Ascomycota and bacteria. This observation may either indicate the relief of inhibition of non-mycorrhizal microorganisms due to removal of ECM competitors, so called the Gadgil effect [76] or simply the decrease of activity of ECM fungi, which is more likely [44]. The observation of the increase in transcription of CAZymes associated with mobilizing reserve compounds-starch, glycogen, and trehalose in winter soil indicates that this is likely a time of nutrient limitation, and biomass may need to be maintained at the costs of metabolic reserves. Starch from plant roots [77] and glycogen from bacteria/ fungi [78] was utilized mainly by bacteria in soil during the winter. Bacteria were found to be the main starch consumers in SIP experiment [79] as well. The use of trehalose and mannitol as energy reserves by ECM during winter starvation has been observed in previous studies [65]. The observed decrease in the transcription of GH and AA by Basidiomycota in winter in soil is consistent with the decrease of transcription of genes related to ECM symbiosis [44], indicating lower activity of the ECM fungi, mainly Basidiomycetes [5].

Contrary to our expectations, the fungal communities in soil did not switch from the utilization of labile $\mathrm{C}$ compounds in summer to more recalcitrant carbohydrates in winter. Instead, the transcription of genes involved in lignin, cellulose, and xylan degradation was increased in the summer and the transcription of genes degrading simple $C$ compounds such as $\alpha$ and $\beta$-glucosidases and amylases was similar in winter and summer. However, we hypothesize that in winter ECM fungi utilize $\alpha$-glucosidases and amylases to survive on storage compounds, while in summer they thrive on root exudates, degradation of which, fuel the production of ligninolytic enzymes in search of ECM fungi for $\mathrm{N}$ in recalcitrant $\mathrm{OM}$ [63]. It was demonstrated previously that summer microbial community decomposes labile $\mathrm{C}$ sources, such as root exudates or glucose, rapidly [80-82], and there is experimental evidence that labile substrates may prime decomposition of recalcitrant OM [83-85]. An alternative explanation, such as that seasonal differences in transcription of CAZymes are driven by temperature is less plausible, because it logically suggests the lower activity of both fungi and bacteria in winter but the decrease of trnascription was specific only for ECM fungi [44]. Although we still lack an understanding of the differences in metabolic resting states in fungi and bacteria, the most plausible solution to the problem of decreased transcription in winter in ECM fungi seems to be diminished supply of $\mathrm{C}$ from the symbiotic trees. Although we did not follow the seasonal changes in DOC and SOC composition, our results support the hypothesis that $C$ priming may be necessary for the decomposition of complex biopolymers by fungi.

\section{Conclusions}

Organisms in coniferous litter and soil possess a diverse set of enzymes that participate in decomposition of 
complex C compounds. Microorganisms are the most important producers of these enzymes, especially $\mathrm{GH}$ and AA CAZymes, with fungi strongly dominating transcription in litter and equal contributions of bacteria and fungi in soil. Composition of microbial community, as far as phyla representations, remains stable across the year, but gene transcription shows seasonality in terms of different abundance of CAZymes transcripts assigned to different microorganisms and their share. Our results indicate that transcription of CAZymes involved in fungal biomass turnover is higher in summer than in winter, while the use of reserve compounds such as starch or trehalose is high in winter. Seasonality of gene transcription is especially high in soil where summer is characterized by high transcription of ligninolytic and cellulolytic CAZymes. Although, both fungi and bacteria contribute to CAZy transcription, our results confirmed the leading role of fungi in the degradation processes as confirmed by the fact that thy produced more than half the observed CAZymes.

\section{Additional files}

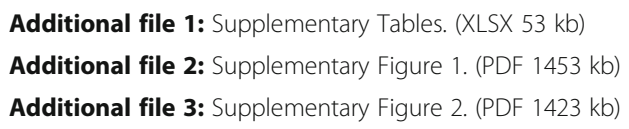

\section{Abbreviations}

AA: Auxiliary carbohydrate-active enzymes,; C: Carbon; CAZy: Carbohydrate active enzymes; ECM: Ectomycorrhizal fungi; FPPD: Fungal-predicted protein database; GH: Glycoside hydrolases; N: Nitrogen; OM: Organic matter

\section{Acknowledgements}

Not applicable.

\section{Funding}

This work was supported by the Czech Science Foundation (16-08916S), the Ministry of Education, Youth and Sports of the Czech Republic (LD15086, LM2015055), and by the research concept of the Institute of Microbiology of the CAS (RVO61388971). LZ was supported by the Grant Agency of the Charles University (260214).

\section{Availability of data and materials}

The datasets supporting the conclusions of this article are available in the MG-RAST repository (http://metagenomics.anl.gov/). Contig metagenomic sequences are stored under number 4627252.3 and that of metatranscriptome as 4544233.3 .

\section{Authors' contributions}

$\mathrm{LZ}$ and $\mathrm{PB}$ designed the study and performed the experiment. TV and $\mathrm{AH}$ performed bioinformatic analyses including the assembly and annotation of the metagenome and metatranscriptome. BH and VL classified, identified, and annotated CAZYmes. All authors collaborated in data analysis. LZ and PB wrote the first draft of the manuscript which was modified by all authors.

\section{Ethics approval}

Not applicable.

\section{Consent for publication}

Not applicable.

\section{Competing interests}

The authors declare that they have no competing interests.

\section{Publisher's Note}

Springer Nature remains neutral with regard to jurisdictional claims in published maps and institutional affiliations.

\section{Author details}

${ }^{1}$ Institute of Microbiology of the CAS, Vídeňská 1083, 14220 Praha 4, Czech Republic. ${ }^{2}$ Faculty of Science, Charles University, Albertov 6, 12843 Praha 2, Czech Republic. ${ }^{3}$ Architecture et Fonction des Macromolécules Biologiques, CNRS, Aix-Marseille Université, Marseille, France. ${ }^{4}$ INRA, USC 1408 AFMB, Marseille, France. ${ }^{5}$ Department of Biological Sciences, King Abdulaziz University, Jeddah, Saudi Arabia. ${ }^{6}$ lowa State University, Ames, IA, USA.

Received: 16 August 2017 Accepted: 12 September 2017

Published online: 18 September 2017

\section{References}

1. Scharlemann JPW, Tanner EVJ, Hiederer R, Kapos V. Global soil carbon: understanding and managing the largest terrestrial carbon pool. Carbon Manag. 2014;5:81-91.

2. Prescott CE, Grayston SJ. Tree species influence on microbial communities in litter and soil: current knowledge and research needs. For Ecol Manag. 2013;309:19-27.

3. Clemmensen KE, Bahr A, Ovaskainen O, Dahlberg A, Ekblad A, Wallander $\mathrm{H}_{\text {, }}$ Stenlid J, Finlay RD, Wardle DA, Lindahl BD. Roots and associated fungi drive long-term carbon sequestration in boreal forest. Science. 2013;339:1615-8.

4. Högberg MN, Briones MJl, Keel SG, Metcalfe DB, Campbell C, Midwood AJ, Thornton B, Hurry V, Linder S, Näsholm T, et al. Quantification of effects of season and nitrogen supply on tree below-ground carbon transfer to ectomycorrhizal fungi and other soil organisms in a boreal pine forest. New Phytol. 2010;187:485-93.

5. Baldrian $P$, Kolařík M, Štursová M, Kopecký J, Valášková V, Větrovský T, Žifčáková L, Šnajdr J, Rídl J, Vlček C, et al. Active and total microbial communities in forest soil are largely different and highly stratified during decomposition. ISME J. 2012;6:248-58.

6. Schnecker J, Wild B, Takriti M, Eloy Alves RJ, Gentsch N, Gittel A, Hofer A, Klaus K, Knoltsch A, Lashchinskiy N, Mikutta R, Richter A. Microbial community composition shapes enzyme patterns in topsoil and subsoil horizons along a latitudinal transect in western Siberia. Soil Biol Biochem. 2015:83:106-15.

7. Wilkinson JF. Carbon and energy storage in bacteria. J Gen Microbiol. 1963:32:171-6.

8. Nehls U. Mastering ectomycorrhizal symbiosis: the impact of carbohydrates. J Exp Bot. 2008;59:1097-108.

9. Druebert C, Lang C, Valtanen K, Polle A. Beech carbon productivity as driver of ectomycorrhizal abundance and diversity. Plant Cell Environ. 2009;32:992-1003.

10. López-Mondéjar R, Vořǐšková J, Větrovský T, Baldrian P. The bacterial community inhabiting temperate deciduous forests is vertically stratified and undergoes seasonal dynamics. Soil Biol Biochem. 2015;87:43-50.

11. Lindahl BD, Ihrmark K, Boberg J, Trumbore SE, Hogberg P, Stenlid J, Finlay RD. Spatial separation of litter decomposition and mycorrhizal nitrogen uptake in a boreal forest. New Phytol. 2007;173:611-20.

12. Lombard V, Ramulu HG, Drula E, Coutinho PM, Henrissat B. The carbohydrate-active enzymes database (CAZy) in 2013. Nucleic Acids Res. 2014;42:D490-5.

13. Kellner $\mathrm{H}$, Vandenbol M. Fungi unearthed: transcripts encoding lignocellulolytic and chitinolytic enzymes in forest soil. PLoS One. 2010;5:e10971.

14. Damon C, Lehembre F, Oger-Desfeux C, Luis P, Ranger J, Fraissinet-Tachet L, Marmeisse R. Metatranscriptomics reveals the diversity of genes expressed by eukaryotes in forest soils. PLoS One. 2012;7:e28967.

15. Schneider T, Keiblinger KM, Schmid E, Sterflinger-Gleixner K, Ellersdorfer G, Roschitzki B, Richter A, Eberl L, Zechmeister-Boltenstern S, Riedel K. Who is who in litter decomposition? Metaproteomics reveals major microbial players and their biogeochemical functions. ISME J. 2012;6:1749-62.

16. Eichorst SA, Kuske CR. Identification of cellulose-responsive bacterial and fungal communities in geographically and edaphically different soils by using stable isotope probing. Appl Environ Microbiol. 2012;78:2316-27. 
17. Leung HTC, Maas KR, Wilhelm RC, Mohn WW. Long-term effects of timber harvesting on hemicellulolytic microbial populations in coniferous forest soils. ISME J. 2016;10:363-75.

18. Rime T, Hartmann M, Stierli B, Anesio AM, Frey B. Assimilation of microbial and plant carbon by active prokaryotic and fungal populations in glacial forefields. Soil Biol Biochem. 2016:98:30-41.

19. Štursová M, Žifčáková L, Leigh MB, Burgess R, Baldrian P. Cellulose utilization in forest litter and soil: identification of bacterial and fungal decomposers. FEMS Microbiol Ecol. 2012;80:735-46.

20. Brabcová V, Nováková M, Davidová A, Baldrian P. Dead fungal mycelium in forest soil represents a decomposition hotspot and a habitat for a specific microbial community. New Phytol. 2016;210:1369-81.

21. Stres B, Danevèiè T, Pal L, Mrkonjiæ M, Resman L, Leskovec S, et al. Influence of temperature and soil water content on bacterial, archaeal and denitrifying microbial communities in drained fen grassland soil microcosms. FEMS Microbiol Ecol. 2008;66:110-22.

22. Tabuchi H, Kato K, Nioh I. Season and soil management affect soil microbial communities estimated using phospholipid fatty acid analysis in a continuous cabbage (Brassica oleracea var. capitata) cropping system. Soil Sci Plant Nutr. 2008;54:369-78.

23. Cleveland CC, Nemergut DR, Schmidt SK, Townsend AR. Increases in soil respiration following labile carbon additions linked to rapid shifts in soil microbial community composition. Biogeochemistry. 2007;82:229-40.

24. Waldrop MP, Firestone MK. Seasonal dynamics of microbial community composition and function in oak canopy and open grassland soils. Microb Ecol. 2006;52:470-9.

25. Koch O, Tscherko D, Kandeler E. Temperature sensitivity of microbial respiration, nitrogen mineralization, and potential soil enzyme activities in organic alpine soils. Glob Biogeochem Cycles. 2007;21:GB4017.

26. Horz H-P, Barbook A, Field CB, Bohannan BJM. Ammonia-oxidizing bacteria respond to multifactorial global change. Proc Natl Acad Sci U S A. 2004;101: 15136-41.

27. Buckley DH, Schmidt TM. Exploring the biodiversity of soil: a microbial rainforest. In: Staley JT, Reysenbach $A L$, editors. Biodiversity of microbial life. New York: Wiley-Liss; 2002. p. 183-208.

28. Kuffner M, Hai B, Rattei T, Melodelima C, Schloter M, ZechmeisterBoltenstern S, Jandl R, Schindlbacher A, Sessitsch A. Effects of season and experimental warming on the bacterial community in a temperate mountain forest soil assessed by 165 rRNA gene pyrosequencing. FEMS Microbiol Ecol. 2012;82:551-62.

29. Wallenstein MD, McMahon SK, Schimel JP. Seasonal variation in enzyme activities and temperature sensitivities in Arctic tundra soils. Glob Chang Biol. 2009;15:1631-9.

30. Wittmann C, Kahkonen MA, Ilvesniemi H, Kurola J, Salkinoja-Salonen MS. Areal activities and stratification of hydrolytic enzymes involved in the biochemical cycles of carbon, nitrogen, sulphur and phosphorus in podsolized boreal forest soils. Soil Biol Biochem. 2004;36:425-33.

31. Baldrian P, Snajdr J, Merhautova V, Dobiasova P, Cajthaml T, Valaskova V. Responses of the extracellular enzyme activities in hardwood forest to soil temperature and seasonality and the potential effects of climate change. Soil Biol Biochem. 2013;56:60-8.

32. Zhang X, Wang W, Chen W, Zhang N, Zeng H. Comparison of seasonal soil microbial process in snow-covered temperate ecosystems of northern China. PLoS One. 2014;9:e92985.

33. Mundra S, Bahram M, Tedersoo L, Kauserud H, Halvorsen R, Eidesen PB. Temporal variation of Bistorta Vivipara-associated ectomycorrhizal fungal communities in the high Arctic. Mol Ecol. 2015;24:6289-302.

34. Baldrian P. Enzymes of Saprotrophic Basidiomycetes. Ecology of Saprotrophic Basidiomycetes. 2008;28:19-41.

35. Jumpponen A, Jones KL, Mattox D, Yaege C. Massively parallel 454-sequencing of fungal communities in Quercus spp. ectomycorrhizas indicates seasonal dynamics in urban and rural sites. Mol Ecol. 2010;19:41-53.

36. Voříšková J, Brabcová V, Cajthaml T, Baldrian P. Seasonal dynamics of fungal communities in a temperate oak forest soil. New Phytol. 2014;201:269-78.

37. Wallander H, Nilsson LO, Hagerberg D, Baath E. Estimation of the biomass and seasonal growth of external mycelium of ectomycorrhizal fungi in the field. New Phytol. 2001;151:753-60.

38. Davey M, Heegaard LE, Halvorsen R, Ohlson M, Kauserud H. Seasona trends in the biomass and structure of bryophyte-associated fungal communities explored by 454 pyrosequencing. New Phytol. 2012;195:844-56.
39. Santalahti M, Sun H, Jumpponen A, Pennanen T, Heinonsalo J, Baldrian P. Vertical and seasonal dynamics of fungal communities in boreal Scots pine forest soil. FEMS Microbiol Ecol. 2016;92:170.

40. Stober C, George E, Persson H. Root growth and response to nitrogen. In: Schulze ED, editor. Carbon and nitrogen cycling in European forest ecosystems: Berlin: Springer; 2000. p. 99-121.

41. Rasche F, Knapp D, Kaise C r, Koranda M, Kitzler B, Zechmeister-Boltenstern S, Richter A, Sessitsch A. Seasonality and resource availability control bacterial and archaeal communities in soils of a temperate beech forest. ISME J. 2011;5:389-402.

42. Lipson DA. Relationships between temperature responses and bacterial community structure along seasonal and altitudinal gradients. FEMS Microbiol Ecol. 2007:59:418-27.

43. Kaiser C, Koranda M, Kitzler B, Fuchslueger L, Schnecker J, Schweiger P, Rasche F, Zechmeister-Boltenstern S, Sessitsch A, Richter A. Belowground carbon allocation by trees drives seasonal patterns of extracellular enzyme activities by altering microbial community composition in a beech forest soil. New Phytol. 2010;187:843-58.

44. Žifčáková L, Větrovský T, Howe A, Baldrian P. Microbial activity in forest soil reflects the changes in ecosystem properties between summer and winter. Environ Microbiol. 2016;18:288-301.

45. Bolger AM, Lohse M, Usadel B. Trimmomatic: a flexible trimmer for Illumina sequence data. Bioinformatics. 2014;30:2114-20.

46. Howe AC, Jansson JK, Malfatti SA. Tackling soil diversity with the assembly of large, complex metagenomes. Proc Natl Acad Sci USA. 2014;111:4904-9.

47. Pell J, Hintze A, Canino-Koning R, Howe A, Tiedje JM, Brown CT. Scaling metagenome sequence assembly with probabilistic de Bruijn graphs. Proc Natl Acad Sci U S A. 2012;109:13272-7.

48. Zerbino DR, Birney E. Velvet: algorithms for de novo short read assembly using de Bruijn graphs. Genome Res. 2008;18:821-9.

49. Fu L, Niu B, Zhu Z, Wu S, Li W. CD-HIT: accelerated for clustering the nextgeneration sequencing data. Bioinformatics. 2012;28:3150-2.

50. Li W, Godzik A. Cd-hit: a fast program for clustering and comparing large sets of protein or nucleotide sequences. Bioinformatics. 2006;22:1658-9.

51. Sommer DD, Delcher AL, Salzberg SL, Pop M. Minimus: a fast, lightweight genome assembler. BMC Bioinformatics. 2007;8:64.

52. Meyer F, Paarmann D, D'Souza M, Olson R, Glass EM, Kubal M, Paczian T, Rodriguez A, Stevens R, Wilke A, et al. The metagenomics RAST server-a public resource for the automatic phylogenetic and functional analysis of metagenomes. BMC Bioinformatics. 2008;9:386.

53. Levasseur A, Drula E, Lombard V, Coutinho PM, Henrissat B. Expansion of the enzymatic repertoire of the CAZy database to integrate auxiliary redox enzymes. Biotechnol Biofuels. 2013;6:41.

54. Langmead B, Trapnell C, Pop M, Salzberg SL. Ultrafast and memory-efficient alignment of short DNA sequences to the human genome. Genome Biol. 2009;10:10.

55. R Core Team. R: A language and environment for statistical computing. Vienna: R Foundation for Statistical Computing; 2014.

56. Oksanen J, Blanchet FG, Friendly M, Kindt R, Legendre P, McGlinn D, Minchin PR, O'Hara RB, Simpson GL, Solymos P et al. Vegan: community ecology package. R package version 2.4-0. https://CRAN.R-project.org/ package=vegan. 2016 .

57. Hesse CN, Mueller RC, Vuyisich M, Gallegos-Graves L, Gleasner CD, Zak DR, Kuske CR. Forest floor community metatranscriptomes identify fungal and bacterial responses to $\mathrm{N}$ deposition in two maple forests. Front Microbiol. 2015;6:337.

58. Ivanova AA, Wegner C-E, Kim Y, Liesack W, Dedysh SN. Identification of microbial populations driving biopolymer degradation in acidic peatlands by metatranscriptomic analysis. Mol Ecol. 2016;25:4818-35.

59. Pold G, Billings AF, Blanchard JL, Burkhardt DB, Frey SD, Melillo JM, Schnabel J, van Diepen LTA, DeAngelis KM. Long-term warming alters carbohydrate degradation potential in temperate forest soils. Appl Environ Microbiol. 2016;82:6518-30.

60. Fierer N, Leff JW, Adams BJ, Nielsen UN, Bates ST, Lauber CL, Owens S, Gilbert JA, Wall DH, Caporaso JG. Cross-biome metagenomic analyses of soil microbial communities and their functional attributes. Proc Natl Acad Sci U S A. 2011;109:21390-5.

61. Struhl K. Fundamentally different logic of gene regulation in eukaryotes and prokaryotes. Cell. 1999 Jul;98(1):1-4.

62. Kollmar M, Kollmar L, Hammesfahr B, Simm D. diArk - the database for eukaryotic genome and transcriptome assemblies in 2014. Nucleic Acids Res. 2015:43:D1107-12. 
63. Lindahl BD, Tunlid A. Ectomycorrhizal fungi-potential organic matter decomposers, yet not saprotrophs. New Phytol. 2015;205:1443-7.

64. Baldrian P. The forest microbiome: diversity. Complexity and Dynamics FEMS Microbiol Rev. 2017:41:109-30.

65. Nehls $U$, Gohringer F, Wittulsky S, Dietz S. Fungal carbohydrate support in the ectomycorrhizal symbiosis: a review. Plant Biol. 2010;12:292-301.

66. Berlemont R, Martiny AC. Genomic potential for polysaccharide deconstruction in bacteria. Appl Environ Microbiol. 2015;81:1513-9.

67. Lladó S, Žifčáková L, Větrovský T, Eichlerová I, Baldrian P. Functional screening of abundant bacteria from acidic forest soil indicates the metabolic potential of Acidobacteria subdivision 1 for polysaccharide decomposition. Biol Fertil Soils. 2016;52:251-60.

68. López-Mondéjar R, Zühlke D, Becher D, Riedel K, Baldrian P. Cellulose and hemicellulose decomposition by forest soil bacteria proceeds by the action of structurally variable enzymatic systems. Sci Rep. 2016:6:25279.

69. van der Wal A, Geydan TD, Kuyper TW, de Boer W. A thready affair: linking fungal diversity and community dynamics to terrestrial decomposition processes. FEMS Microbiol Rev. 2013;37:477-94.

70. Liebminger E, Hüttner S, Vavra U, Fischl R, Schoberer J, Grass J, et al. Class I alpha-mannosidases are required for $\mathrm{N}$-glycan processing and root development in Arabidopsis thaliana. Plant Cell. 2009;21:3850-67.

71. Sterjiades R, Dean JFD, Eriksson K-EL. Laccase from sycamore maple (Acer pseudoplatanus) polymerizes Monolignols. Plant Physiol. 1992;99:1162-8.

72. McCaig BC, Meagher RB, Dean JF. Gene structure and molecular analysis of the laccase-like multicopper oxidase (LMCO) gene family in Arabidopsis thaliana. Planta. 2005:221:619-36.

73. Fierer N, Jackson RB. The diversity and biogeography of soil bacterial communities. Proc Natl Acad Sci U S A. 2006;103:626-31.

74. Wallenstein MD, McMahon S, Schimel J. Bacterial and fungal community structure in Arctic tundra tussock and shrub soils. FEMS Microbiol Ecol. 2007:59:428-35.

75. Krave AS, Lin B, Braster M, Laverman AM, van Straalen NM, Röling WF, et al. Stratification and seasonal stability of diverse bacterial communities in a Pinus merkusii (pine) forest soil in central java, Indonesia. Environ Microbiol. 2002:4:361-73.

76. Fernandez CW, Kennedy PG. Revisiting the 'Gadgil effect': do interguild fungal interactions control carbon cycling in forest soils? New Phytol. 2016; 209:1382-94.

77. Ericsson A, Persson H. Seasonal changes in starch reserves and growth of fine roots of 20-year old Scots pines. Ecol Bull. 1980;32:239-50.

78. Wilson WA, Roach PJ, Montero M, Baroja-Fernandez E, Munoz FJ, Eydallin G, Viale AM, Pozueta-Romero J. Regulation of glycogen metabolism in yeast and bacteria. FEMS Microbiol Rev. 2010;34:952-85.

79. Rinnan R, Bååth E. Differential utilization of carbon substrates by bacteria and fungi in tundra soil. Appl Environ Microbiol. 2009;75:3611-20.

80. Dennis PG, Miller AJ, Hirsch PR. Are root exudates more important than other sources of rhizodeposits in structuring rhizosphere bacterial communities? FEMS Microbiol Ecol. 2010;72:313-27.

81. Jones RT, Robeson MS, Lauber CL, Hamady M, Knight R, Fierer N. A comprehensive survey of soil acidobacterial diversity using pyrosequencing and clone library analyses. ISME J. 2009:3:442-53.

82. Blagodatskaya E, Blagodatsky S, Anderson T, Kuzyakov Y. Priming effects in Chernozem induced by glucose and $\mathrm{N}$ in relation to microbial growth strategies. Appl Soil Ecol. 2007;37:95-105.

83. Kuzyakov Y. Priming effects: interactions between living and dead organic matter. Soil Biol Biochem. 2010;42:1363-71.

84. Dijkstra FA, Cheng WX. Interactions between soil and tree roots accelerate long-term soil carbon decomposition. Ecol Lett. 2007;10:1046-53.

85. Talbot JM, Allison SD, Treseder KK. Decomposers in disquise: mycorrhizal fungi as regulators of soil $\mathrm{C}$ dynamics in ecosystems under global change. Funct Ecol. 2008;22:955-63.

\section{Submit your next manuscript to BioMed Central and we will help you at every step:}

- We accept pre-submission inquiries

- Our selector tool helps you to find the most relevant journal

- We provide round the clock customer support

- Convenient online submission

- Thorough peer review

- Inclusion in PubMed and all major indexing services

- Maximum visibility for your research

Submit your manuscript at www.biomedcentral.com/submit
Biomed Central 